\title{
Gold nanoparticles and electroporation impose both separate and synergistic radiosensitizing effects in HT-29 tumor cells: an in vitro study
}

This article was published in the following Dove Press journal:

International Journal of Nanomedicine

21 February 2017

Number of times this article has been viewed

\author{
Zohre Rezaee ${ }^{1,2}$ \\ Ali Yadollahpour ${ }^{1,2}$ \\ Vahid Bayati' \\ Fereshteh Negad Dehbashi' \\ 'Cellular and Molecular Research \\ Center, Ahvaz Jundishapur \\ University of Medical Sciences, \\ Avhaz, Iran; '2Department of Medical \\ Physics, School of Medicine, Ahvaz \\ Jundishapur University of Medical \\ Sciences, Ahvaz, Iran
}

Background and objective: Radiation therapy (RT) is the gold standard treatment for more than half of known tumors. Despite recent improvements in RT efficiency, the side effects of ionizing radiation (IR) in normal tissues are a dose-limiting factor that restricts higher doses in tumor treatment. One approach to enhance the efficiency of RT is the application of radiosensitizers to selectively increase the dose at the tumor site. Gold nanoparticles (GNPs) and electroporation (EP) have shown good potential as radiosensitizers for RT. This study aims to investigate the sensitizing effects of EP, GNPs, and combined GNPs-EP on the dose enhancement factor (DEF) for $6 \mathrm{MV}$ photon energy.

Methods: Radiosensitizing effects of EP, GNPs, and combinations of GNPs-EP were comparatively investigated in vitro for intestinal colon cancer (HT-29) and Chinese hamster ovary $(\mathrm{CHO})$ cell lines by MTT assay and colony formation assay at $6 \mathrm{MV}$ photon energy in six groups: IR (control group), GNPs+IR, GNPs (24 h)+IR, EP+IR, GNPs+EP+IR, and GNPs (24 h)+EP+IR.

Results: Treatment of both cell lines with EP, GNPs, and combined GNPs-EP significantly enhanced the response of cells to irradiation. However, the HT-29 showed higher DEF values for all groups. In addition, the DEF value for HT-29 cells for GNPs+IR, GNPs (24 h)+IR, EP+IR, GNPs+EP+IR, and GNPs (24 h)+EP+IR was, respectively, 1.17, 1.47, 1.36, 2.61, and 2.89, indicating synergistic radiosensitizing effect for the GNPs ( $24 \mathrm{~h})+\mathrm{EP}+\mathrm{IR}$ group. Furthermore, the synergistic effect was observed just for HT-29 tumor cell lines.

Conclusion: Combined GNPs-EP protocols induced synergistic radiosensitizing effect in HT-29 cells, and the effect is also tumor specific. This combined therapy can be beneficially used for the treatment of intrinsically less radiosensitive tumors.

Keywords: gold nanoparticles, radiosensitizer, electroporation, dose enhancement factor, synergistic effect

\section{Introduction}

Radiation therapy is the gold standard treatment option for more than half of cancer patients due to its ability to kill malignant cells and shrink tumors. ${ }^{1}$ It prevents tumor cell growth through bombardment of the tumor with ionizing radiation (IR). IR induces DNA damage by direct or indirect action through the generation of reactive oxygen species (ROS). ${ }^{2}$ Unfortunately, there is no discrimination between normal and malignant tissues in absorption of IRs, and thus doses of radiation must be limited to spare healthy surrounding tissue. ${ }^{3}$ One approach to increase discrimination between tumors and healthy tissues and thereby increasing the efficiency of radiation therapy is the use of radiosensitizer to preferably enhance dose at the site of tumor. ${ }^{4-6}$ In recent years,
Correspondence: Ali Yadollahpour Department of Medical Physics, School of Medicine, Ahvaz Jundishapur University of Medical Sciences, Golestan Blvd., Ahvaz 61357-33118, Iran

Fax +98 613 312028

Email yadollahpour.a@gmail.com (c)
hereby accept the Terms. Non-commercial uses of the work are permitted without any further permission from Dove Medical Press Limited, provided the work is properly attributed. For permission hereby accept the Terms. Non-commercial uses of the work are permitted without any further permission from Dove Mediect
for commercial use of this work, please see paragraphs 4.2 and 5 of our Terms (https://www.dovepress.com/terms.php). 
various radiosensitizers have been developed to increase the outcome of radiation therapy. Material with high atomic number (Z) such as gold nanoparticles (GNPs) ${ }^{7,8}$ and physical approaches such as electroporation (EP $)^{9,10}$ are two important examples to achieve this goal.

GNPs have been previously shown to improve the effect of radiotherapy in vitro ${ }^{11,12}$ and in vivo. ${ }^{13,14}$ GNPs have several characteristics that make them attractive for using with radiation therapy including small size (1-100 nm), biocompatibility, preferential passive accumulation in tumor, and the feasibility of surface modification to actively target cancerous cells. ${ }^{15-18}$ GNPs with high $\mathrm{Z}$ increase the cross section of photoelectric absorption and pair production interaction in the $\mathrm{keV}$ and $\mathrm{MeV}$ energy range, respectively, and thus enhance the delivering dose to the target tumor. ${ }^{19,20}$ Moreover, the interaction of X-ray with GNPs can release free radicals, thereby damaging DNA. Furthermore, GNPs have the ability to enter the mitochondria and induce apoptotic death. ${ }^{21}$

EP is a physical process through which applying short intense electric pulses increases cell membrane permeability. ${ }^{22-24}$ In normal physiological conditions, the electric conductivity of cytoplasm and extracellular medium is much higher than the conductivity of the cell membrane. Thus, when an external electric field is applied to this lipid membrane, the anode-facing and cathode-facing side become hyperpolarized and depolarized, respectively, and a transmembrane potential is induced on the exposed cell..$^{25,26}$ Equation (1) is generally used to describe this induced transmembrane potential:

$$
\Delta V_{m}=f E_{e x t} r \cos \varnothing
$$

where $V_{m}$ denotes transmembrane potential, $f$ a factor that describes the effect of the cell on the extracellular field distribution, $E_{\text {ext }}$ the external electric field, $r$ the radius of cell and $\varnothing$ is the polar angle with respect to the external field. If $\Delta V_{m}$ is larger than a critical value $(0.2-1.0 \mathrm{~V})$, the EP is occurred, and the nanoscale pores are appeared in membrane. ${ }^{27,28}$ This phenomenon depends on pulse parameters such as amplitude, pulse frequency, pulse duration and number of pulse, and also on experimental conditions, for example, osmotic pressure, temperature, and conductivity of EP buffer, etc. ${ }^{27,29}$ If these electric parameters are chosen properly, the process of EP is reversible, ${ }^{30}$ and upon further increase of the electric parameters, the EP phenomenon becomes irreversible, which kills the cells. ${ }^{31,32} \mathrm{EP}$ is routinely employed to transport nonpermeant molecules such as DNA, dyes, proteins, and chemotherapeutic drugs into the cell. ${ }^{33-35}$ However, it has been demonstrated that EP can induce oxidative jump and generate ROS. ${ }^{36}$ Gabriel and Teissie ${ }^{37}$ have reported that the generation of ROS is not homogenous and restricted to the electropermeabilized side of the cell membrane. Therefore, this technique can be combined with IR as a radiosensitizer to enhance the outcome of radiation therapy. West ${ }^{10}$ demonstrated that use of EP prior to irradiation can enhance the effect of irradiation by factor of 1.19 .

Previous studies have demonstrated that EP and GNPs have radiosensitizing effects. However, we could not find any study investigating concurrent application of EP and GNPs to increase the sensitivity of cells to IR. Therefore, the present study was designed aiming to investigate the effects of EP and GNPs alone and in combination to increase the efficiency of radiation therapy. We hypothesized that the combination of EP and GNPs would induce synergistic radiosensitizing effect because of the following reasons:

1) EP can increase the uptake of GNPs by cells.

2) The conductivity of EP buffer is increased using GNPs, and this decreases the electric voltage consumed by the EP buffer, thereby improving the efficiency of EP. ${ }^{38}$

3) GNPs act as microelectrodes ${ }^{38}$ and the electropermeabilization of membrane and thereby generation of ROS occurs on different sites of membrane.

\section{Materials and methods Cell culture}

Colorectal cancer (HT-29) and Chinese hamster ovary $(\mathrm{CHO})$ cell lines were purchased from National Cell Bank of Pasteur Institute of Iran (NCBI, C466 and C111) and grown as monolayers in Roswell Park Memorial Institute (RPMI) 1640 medium (BIO-IDEA, B11031, Tehran, Iran) enriched with 10\% fetal bovine serum (FBS; Gibco, Thermo Fisher Scientific, Waltham, MA, USA) and 1\% penicillin/ streptomycin (BIO-IDEA). The cells were routinely subcultured twice a week and maintained at $37^{\circ} \mathrm{C}$ in a humidified atmosphere with $5 \% \mathrm{CO}_{2}$ in an incubator (RS Biotech Galaxy R, West Lothian, UK).

\section{GNPs characterization}

GNPs $(99.95+\%, 15 \mathrm{~nm})$ were purchased from US Research Nanomaterials, Inc. (Houston, TX, USA). To prepare stock solution, the nanoparticles were suspended in deionized water, and other dilutions were performed in culture media immediately before use. The size and morphology of GNPs were estimated by transmission electron microscope (TEM) and scanning electron microscope. According to these 
images, GNPs were spherical, and the average size was $12-15 \mathrm{~nm}$ in diameter (Figure 1A and B). We used GNPs at concentration of $0.1 \mathrm{mM}$.

\section{Study protocol}

To evaluate the radiosensitizing effect of GNPs, EP, and combinations of GNPs and EP, six different experimental groups were designed in this study (Figure 2): irradiation alone as a control group (IR), cells treated with GNPs immediately before irradiation (GNPs+IR), cells incubated with GNPs $24 \mathrm{~h}$ prior to irradiation (GNPs [24 h]+IR), cells exposed electric pulse $10 \mathrm{~min}$ before irradiation (EP+IR), cells treated with both GNPs and EP 10 min before irradiation (GNPs+EP+IR), and cells incubated with GNPs for $24 \mathrm{~h}$ and then receiving EP 10 min prior to irradiation (GNPs [24 h]+EP+IR). Different combinations of EP-GNPs with respect to time intervals between each modality were designed to study some important hypotheses on the mechanisms of actions of each modality.

\section{Electroporation set up}

The sample solution was dispensed into a 1 MM gap cuvette, and a single square pulse with voltage to distance ratio of $1,200 \mathrm{~V} / \mathrm{cm}$ and $100 \mu \mathrm{s}$ duration was delivered using a BioRad Gene Pulser Xcell ${ }^{\mathrm{TM}}$ (Hercules, CA, USA) EP system at room temperature $\left(21^{\circ} \mathrm{C}\right)$. Immediately after EP, the suspension was transferred either to 6-well or 96-well plate based on the assay, and then fresh culture medium was added to the cells. Finally, the plate was irradiated with ionization radiation after $10 \mathrm{~min}$.

\section{Irradiation setup}

The cells were irradiated with megavoltage X-ray (6 MV) using Varian 2100 C/D linear accelerator (Golestan Hospital,
Ahvaz, Iran) at a dose rate of $3 \mathrm{~Gy} / \mathrm{min}$ with a field size of $20 \times 20 \mathrm{~cm}^{2}$. We used a Plexiglass (water equivalent) sheet with $1.5 \mathrm{~cm}$ thickness on top the plate (6-well in clonogenic cell survival assay and 96-well plate in MTT assay) as a build up to produce transient charged particle equilibrium. Moreover, another Plexiglass sheet with the thickness of 6 $\mathrm{cm}$ was placed under the bottom of plate to sufficient production of backscatter.

\section{Evaluation of radiosensitizing effect of GNPs, EP, and GNPs-EP \\ MTT assay}

The cellular response to each treatment at radiation doses of 2 and 4 Gy was assessed using MTT assay kit according to the manufacturer's protocol (Bio-Idea). In this colorimetric method, the mitochondrial dehydrogenase activity of proliferating cells reduces the MTT salt into purple MTT formazan crystals. After incubation of $10^{4}$ treated cells/well for $24 \mathrm{~h}$, $10 \mu \mathrm{L}$ of MTT solution ( $5 \mathrm{mg} / \mathrm{mL}$ ) was added to each well and incubated for additional $4 \mathrm{~h}$. The MTT was reduced to blue formazan crystals due to mitochondrial dehydrogenase activity of living cells. At the end of the incubation time, formazan crystals were dissolved by adding $50 \mu \mathrm{L}$ dimethyl sulfoxide (DMSO) and the plate was placed on the orbital shaker for $20 \mathrm{~min}$. Finally, optical density (OD) at 570-nm wavelength was measured using a spectrophotometer (BioRad, Model 680). The viability rate (\%) of cells in different groups was calculated by the following formula: viability rate $=\left(\right.$ average $\mathrm{OD}_{570 \mathrm{~nm}}$ of treated group/average $\mathrm{OD}_{570 \mathrm{~nm}}$ of the control group) $\times 100 \%$.

\section{Clonogenic cell survival assay}

We used "plating before treatment" protocol to perform clonogenic cell survival assay. ${ }^{39}$ In this regard, the cells
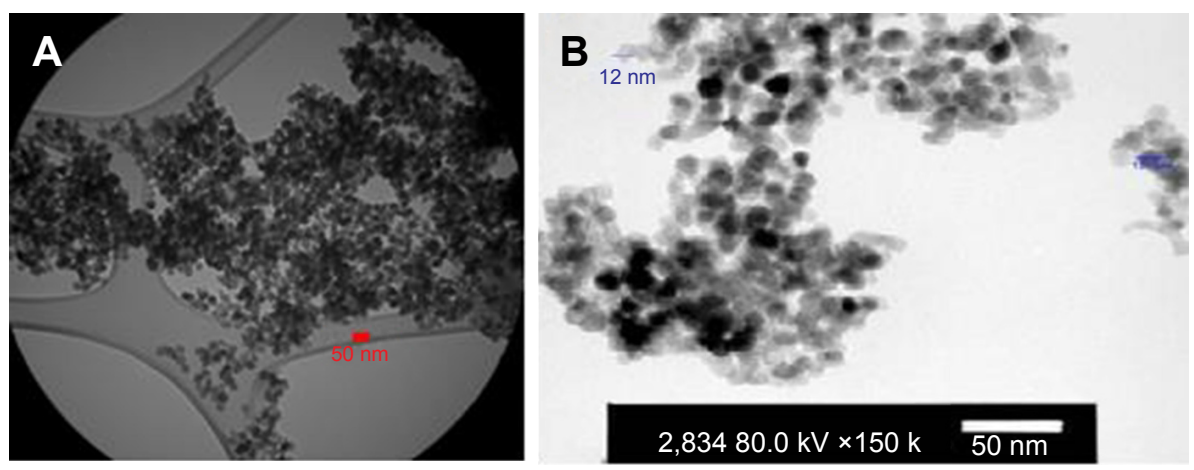

Figure I The images of GNPs. (A) Transmission electron microscope image, (B) scanning electron microscope image. Abbreviation: GNPs, gold nanoparticles. 

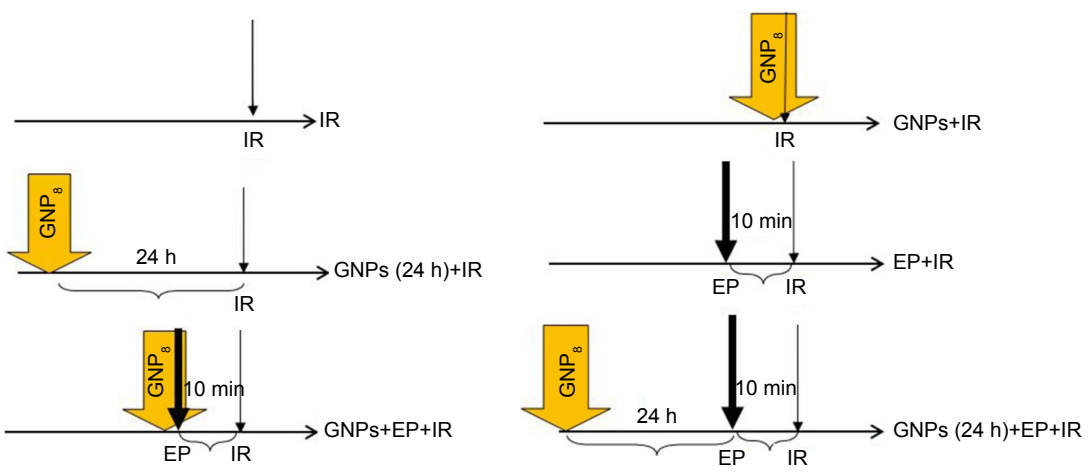

Figure 2 Schematic diagram of the experimental procedures for six different treatment groups. Abbreviations: IR, ionizing radiation; GNPs, gold nanoparticles; EP, electroporation.

were washed twice with phosphate-buffered saline (PBS), trypsinized, centrifuged, and then counted. A known numbers of cells $(100,200,400,1,000$, and 2,000 cells, respectively for irradiation dose of $0,2,4,6$, and $8 \mathrm{~Gy})^{40}$ were treated with predefined treatment protocol (Figure 2). The treated cells were incubated for 14 days to allow them to form large colonies. Then, the cells were fixed and stained with $0.4 \%$ crystal violet, and the visible colonies with more than 50 cells were counted. The plating efficiency (PE) was determined at IR dose of 0 Gy by the following formula: colony number/ plating cell number. The survival fraction (SF) of treatment groups was calculated using the equation: $\mathrm{SF}=$ colony number/(plating cell number $\times \mathrm{PE}$ ). The data were fit to linear quadratic model with the equation of $\mathrm{SF}=\exp ^{(-\alpha \mathrm{D}-\beta \mathrm{DD} 2)}$, and survival curve was estimated using MATLAB software. The dose enhancement factor (DEF) was calculated by dividing of $\mathrm{LD}_{50}(50 \%$ lethal dose $)$ of irradiation alone group with the combined treatment group.

\section{Statistical analysis}

All experiments were performed in replicates of three, and results were reported as mean \pm standard error of mean (SEM). To evaluate the cytotoxicity of GNPs, the difference between untreated control group and those treated with GNPs was assessed by paired $t$-test. In addition, one-way analysis of variance (ANOVA) was used to compare the differences between the treatment groups. The $\alpha$ and $\beta$ parameters of survival curve were calculated with weighted least square regression and SigmaStat statistical software (SPSS Inc., Chicago, IL, USA). In all experiments, the statistical significance was set at $P \leq 0.05$.

\section{Results}

\section{The cytotoxicity of GNPs}

The cytotoxicity of GNPs at a concentration of $0.1 \mathrm{mM}$ on HT-29 and CHO cells was assessed by MTT assay. The SFs of cells after incubation with GNPs for 24,48 , and $72 \mathrm{~h}$ are presented in Figure 3A and B. The analysis of data was performed with paired $t$-test and showed no significant cytotoxicity effect on both cell lines $(P>0.05)$.

\section{Radiosensitivity of GNPs, EP, and GNPs-EP}

\section{Clonogenic cell survival assay}

Figure 4A and B shows the survival curves of HT-29 tumor cells and $\mathrm{CHO}$ normal cells that were treated in different groups. In the control group, treatment of HT-29 and CHO cells with irradiation only resulted in $\mathrm{LD}_{50}$ of $3.97 \mathrm{~Gy}$ and 4.19 Gy, respectively (Table 1). Adding GNPs to culture medium of cells immediately before irradiation decreased the $\mathrm{LD}_{50}$ to $3.37 \mathrm{~Gy}$ in HT-29 and $3.63 \mathrm{~Gy}$ in CHO cells. In this group, GNPs could enhance treatment response by factor of 1.17 and 1.15 in HT-29 and CHO cell lines, respectively. For HT-29 cell line, the $\mathrm{LD}_{50}$ and DEF values, respectively, reached to $2.69 \mathrm{~Gy}$ and 1.47 in the group treated with GNPs for $24 \mathrm{~h}$ before IR. The corresponding values in the $\mathrm{CHO}$ cell lines were, respectively, 3.03 Gy and 1.38. For both cell lines, the $\mathrm{LD}_{50}$ values were significantly lower than the control group $(P<0.05)$. When the cells were exposed to electric pulse prior to irradiation, $\mathrm{LD}_{50}$ of $2.92 \mathrm{~Gy}$ and $\mathrm{DEF}$ of 1.36 for HT-29 cells $(P<0.05)$ and of 3.27 Gy and 1.28 for $\mathrm{CHO}$ cells $(P<0.05)$ were observed. In the GNPs+EP+IR group, treatment of cells with GNPs and EP simultaneously 10 min before irradiation significantly decreased the $\mathrm{LD}_{50}$ values in both cell lines $(P<0.05)$. For this treatment protocol, the DEF was 2.61 in HT-29 and 1.92 in CHO cell lines. In the GNPs $(24 \mathrm{~h})+\mathrm{EP}+\mathrm{IR}$ group, when the $24 \mathrm{~h}$ incubated HT-29 cells with GNPs were exposed to electric pulse 10 min prior to irradiation, the $\mathrm{LD}_{50}$ was further reduced to 1.37 Gy in HT-29 cells and to 1.85 Gy in CHO cell lines. Furthermore, in this group, the highest DEF was achieved (2.89 for HT-29 and 2.26 for CHO cell lines). Moreover, the 
A

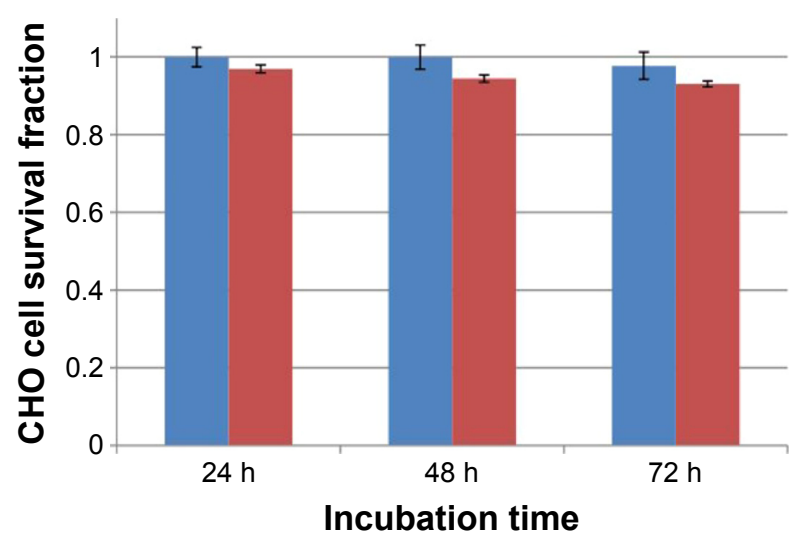

B

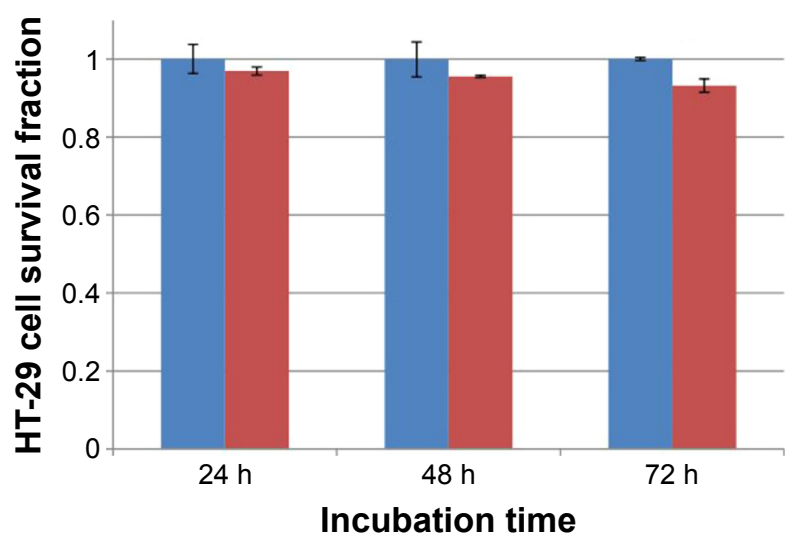

No GNPs $0.1 \mathrm{mM}$ GNPs

Figure 3 (A) Survival fraction of HT-29 cells incubated with GNPs at a concentration of $0.1 \mathrm{mM}$ for 24,48 , and $72 \mathrm{~h}$ compared to nontreated group. None of the groups were statistically significant $(P>0.05)$. (B) Survival fraction of $\mathrm{CHO}$ cells incubated with GNPs at concentration of $0.1 \mathrm{mM}$ for 24,48 , and $72 \mathrm{~h}$ compared to nontreated group. None of the groups were statistically significant $(P>0.05)$.

Abbreviations: $\mathrm{CHO}$, Chinese hamster ovary; GNPs, gold nanoparticles.

DEF values demonstrated that synergistic effect was only observed in the HT-29 cells (Table 1).

\section{MTT assay}

The viability of HT-29 and CHO cells in six different treatment groups was evaluated by MTT assay $24 \mathrm{~h}$ after irradiation with $6 \mathrm{MV}$ X-ray at doses of 2 Gy and 4 Gy
(Figure 5A and B). In the control group (IR), exposing the cells by 2 Gy irradiation alone yielded a viability of $76.94 \% \pm$ $1.2 \%$ and $77.54 \% \pm 0.8 \%$ for HT-29 and CHO cell lines, respectively. The treatment of HT-29 and $\mathrm{CHO}$ cell lines with 4 Gy irradiation alone reduced the viability to $48.3 \% \pm 0.18 \%$ and $48.67 \% \pm 0.72 \%$, respectively. No significant reduction in viability was observed when the both cells were received
A

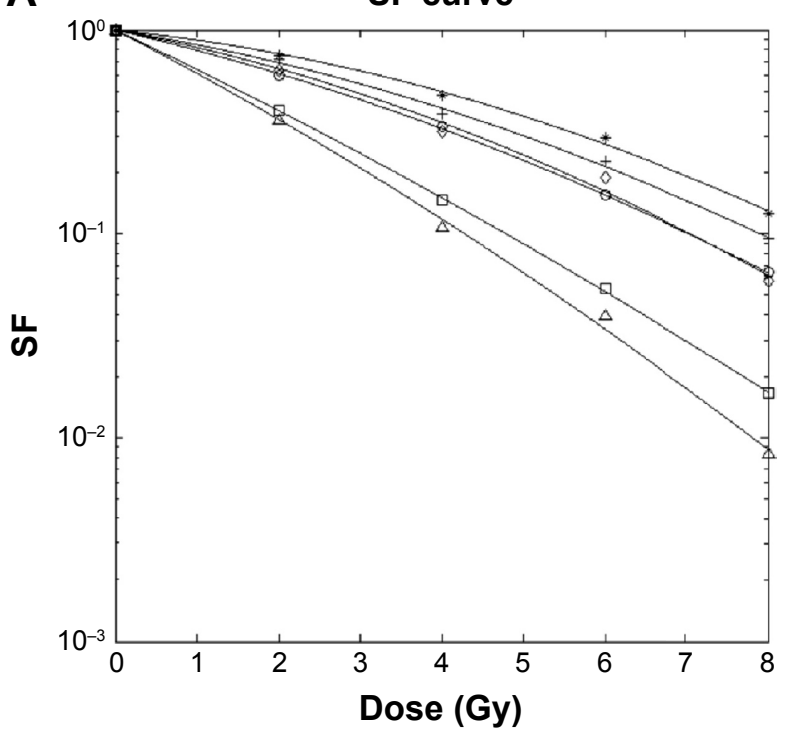

B

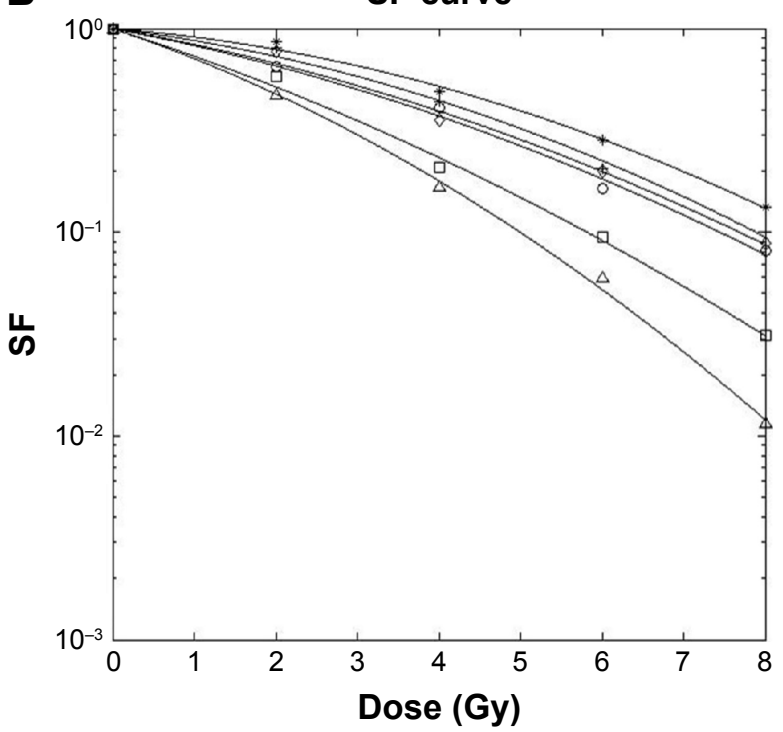

* IR + GNPs+IR $\circ$ GNPs $(24 h)+I R \quad \diamond E P+I R \quad \square$ GNPs+EP+IR $\Delta$ GNPs $(24 h)+E P+I R$

Figure 4 (A) Radiation survival curves of cancerous HT-29 cells treated with six different protocols based on clonogenic assay. (B) Radiation survival curves of CHO cells treated with six different protocols based on clonogenic assay.

Abbreviations: IR, ionizing radiation; GNPs, gold nanoparticles; EP, electroporation; SF, survival fraction. 
Table I Values of $\alpha, \beta, \mathrm{LD}_{50}$, DEF, and $R^{2}$ values of $\mathrm{HT}-29$ and $\mathrm{CHO}$ cells in different groups

\begin{tabular}{|c|c|c|c|c|c|c|c|c|c|c|}
\hline \multirow[t]{2}{*}{ Groups } & \multicolumn{2}{|l|}{$\alpha\left(G y^{-1}\right)$} & \multicolumn{2}{|l|}{$\beta\left(G^{-2}\right)$} & \multicolumn{2}{|c|}{$L_{50}(G y)$} & \multicolumn{2}{|l|}{ DEF } & \multicolumn{2}{|l|}{$R^{2}$} \\
\hline & $\mathrm{CHO}$ & HT-29 & $\mathrm{CHO}$ & HT-29 & $\mathrm{CHO}$ & HT-29 & $\mathrm{CHO}$ & HT-29 & $\mathrm{CHO}$ & HT-29 \\
\hline IR & $0.064 \pm 0.016$ & $0.09 \pm 0.013$ & $0.024 \pm 0.002$ & $0.021 \pm 0.002$ & 4.19 & 3.97 & - & - & 0.997 & 0.997 \\
\hline GNPs+IR & $0.099 \pm 0.018$ & $0.144 \pm 0.013$ & $0.025 \pm 0.003$ & $0.018 \pm 0.002$ & 3.63 & 3.37 & 1.15 & 1.17 & 0.996 & 0.998 \\
\hline GNPs $(24 h)+I R$ & $0.17 \pm 0.017$ & $0.213 \pm 0.013$ & $0.019 \pm 0.003$ & $0.016 \pm 0.002$ & 3.03 & 2.69 & 1.38 & 1.47 & 0.997 & 0.998 \\
\hline$E P+I R$ & $0.145 \pm 0.02$ & $0.174 \pm 0.024$ & $0.02 \pm 0.003$ & $0.02 I \pm 0.004$ & 3.27 & 2.92 & 1.28 & 1.36 & 0.996 & 0.998 \\
\hline GNPs+EP+IR & $0.27 \pm 0.02$ & $0.439 \pm 0.022$ & $0.02 I \pm 0.004$ & $0.008 \pm 0.004$ & 2.18 & 1.52 & 1.92 & 2.61 & 0.995 & 0.998 \\
\hline GNPs $(24$ h)+EP+IR & $0.319 \pm 0.02$ & $0.487 \pm 0.029$ & $0.028 \pm 0.003$ & $0.01 I \pm 0.005$ & 1.85 & 1.37 & 2.26 & 2.89 & 0.998 & 0.997 \\
\hline
\end{tabular}

Note: The values are expressed as mean \pm SEM.

Abbreviations: $\mathrm{LD}_{50}, 50 \%$ lethal dose; $\mathrm{CHO}$, Chinese hamster ovary; IR, ionizing radiation; GNPs, gold nanoparticles; EP, electroporation; DEF, dose enhancement factor; SEM, standard error of mean.

GNPs immediately prior to irradiation $(P>0.05)$. The viability of HT-29 cells that were exposed to irradiation after 24-h incubation with GNPs reached $57.1 \% \pm 1.1 \%$ for 2 Gy and $29.9 \% 6 \pm 1.7 \%$ for $4 \mathrm{~Gy}$ irradiation $(P<0.05)$. The treatment of $\mathrm{CHO}$ cells with the same protocol resulted in a viability rate of $61.19 \% \pm 1.2 \%$ and $38.95 \% \pm 0.5 \%$ for 2 Gy and $4 \mathrm{~Gy}$ irradiation $(P<0.05)$, respectively. By delivering the electric pulse $10 \mathrm{~min}$ before IR, the viability rate of $65.91 \% \pm 0.55 \%$ at a dose of 2 Gy and $34.71 \% \pm 0.93 \%$ at a dose of 4 Gy was obtained for HT-29 cells. Almost equal values were observed
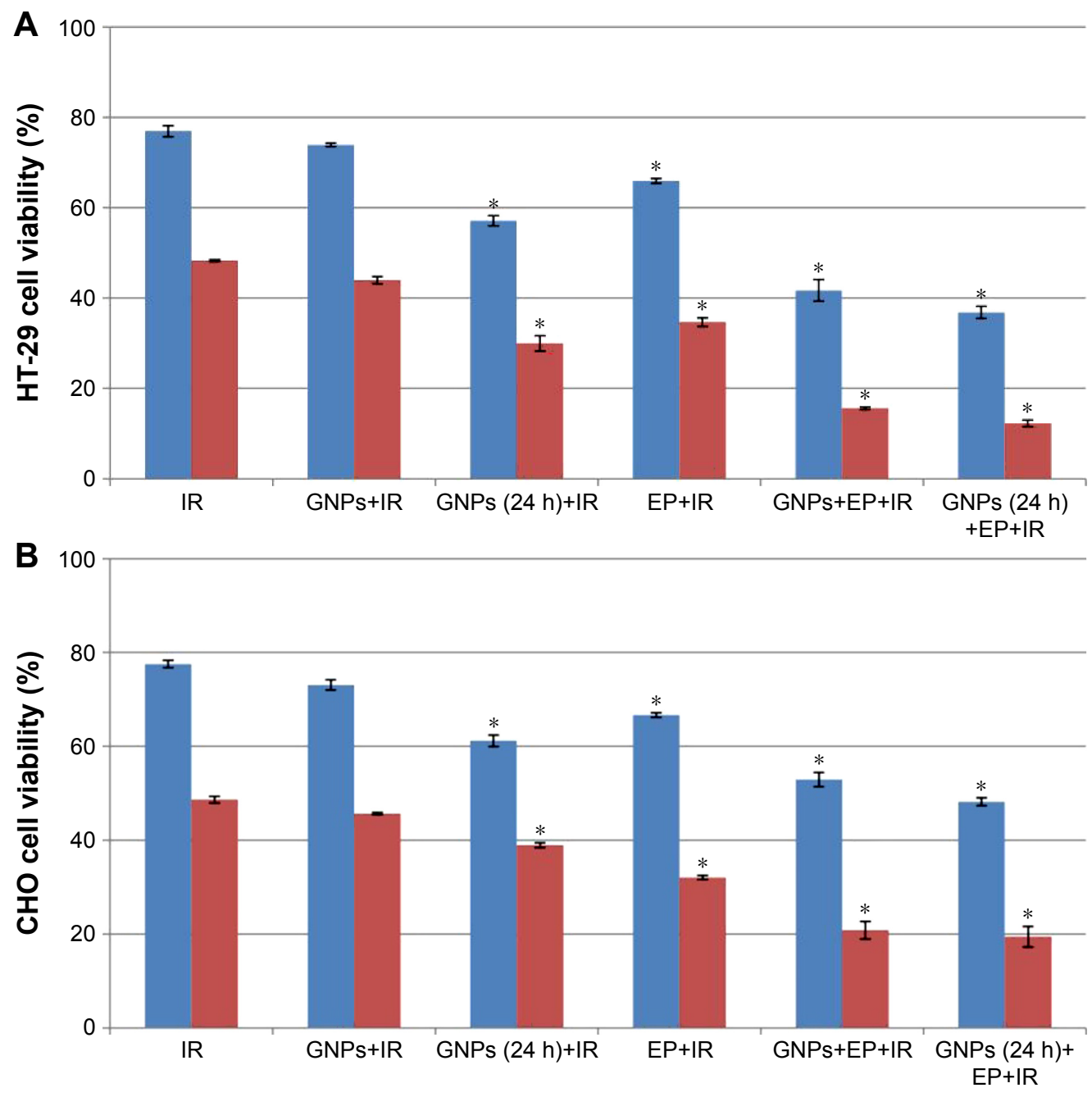

- 2 Gy $\quad 4$ Gy

Figure 5 (A) The viability of HT-29 cells treated with IR, GNPs+IR, GNPs (24 h)+IR, EP+IR, GNPs+EP+IR, and GNPs (24 h)+EP+IR based on MTT assay. *P<0.05. (B) The viability of $\mathrm{CHO}$ cells treated with IR, GNPs+IR, GNPs $(24 \mathrm{~h})+\mathrm{IR}, \mathrm{EP}+\mathrm{IR}, \mathrm{GNPs}+\mathrm{EP}+\mathrm{IR}$, and GNPs $(24 \mathrm{~h})+\mathrm{EP}+\mathrm{IR}$ based on MTT assay. $* P<0.05$.

Abbreviations: $\mathrm{CHO}$, Chinese hamster ovary; IR, ionizing radiation; GNPs, gold nanoparticles; EP, electroporation. 
for $\mathrm{CHO}$ cell lines. Indeed, EP could significantly enhance response of HT-29 and $\mathrm{CHO}$ cells to irradiation $(P<0.05)$. In the GNPs+EP+IR group, application of both GNPs and EP 10 min before irradiation resulted in a higher radiation response of cells. After delivering of $4 \mathrm{~Gy}$ irradiation, only $15.61 \% \pm 0.26 \%$ of HT-29 cells and $52.95 \% \pm 1.5 \%$ of CHO cells were viable $(P<0.05)$. The lowest viability in both radiation doses of $2 \mathrm{~Gy}(36.80 \% \pm 1.35 \%$ for HT-29 cells and $48.19 \% \pm 0.84 \%$ for $\mathrm{CHO}$ cells $)$ and $4 \mathrm{~Gy}(12.29 \% \pm 0.72 \%$ for HT-29 cells and $19.45 \% \pm 2.19 \%$ for CHO cells) was achieved in GNPs $(24 \mathrm{~h})+\mathrm{EP}+\mathrm{IR}$ group $(P<0.05)$. The results of these tests revealed that concurrent applications of GNPs and EP as radiosensitizer can significantly increase the efficiency of radiation therapy.

\section{Discussion}

Radiosensitizing effects of GNPs and EP have been extensively investigated in several in vitro and in vivo studies. However, to our knowledge, there is no published study that investigated the radiosensitizing effects of combined GNPs-EP in any healthy or tumor cell lines. The main objective of this study was to investigate synergistic radiosensitizing effect of combined GNPs-EP to $6 \mathrm{MV}$ X-ray photons. In addition, different combinations of GNPs-EP were investigated to shed more light on the mechanisms of actions of possible radiosensitizing effects.

Our results showed that EP alone could sensitize both HT-29 and CHO cell lines to $6 \mathrm{MV}$ photons with a DEF of 1.36 and 1.28, respectively. Consistent with our result, Kranjc et $\mathrm{al}^{41}$ reported a DEF of 1.25 for LPB sarcoma cell line. Moreover, West ${ }^{10}$ demonstrated that EP can enhance effect of ${ }^{137} \mathrm{Cs}-\gamma$ radiation by a factor of 1.19 . Generally, the oxidative jump at electroporated sites of membrane and production of ROS are the probable radiosensitization mechanism of EP. ${ }^{37,42}$ Shil et $\mathrm{al}^{43}$ measured the level of generated ROS induced by EP and reported that the ROS level under the combined EP-irradiation group was significantly higher than irradiation alone group.

In the GNPs+IR group, GNPs did not significantly enhance the effect of IR due to having not enough time for GNPs to enter and accumulate in the target cells. As we know, when irradiation interacts with GNPs, free radicals are produced that further generate ROS. These ROS are very toxic for tumor cells, but have very short diffusion range about 10 $\mathrm{nm}$. Therefore, the accumulation of GNPs in the target cells is essential to induce death in the tumor cells. ${ }^{44}$ However, in the GNPs+IR group, there was not enough time between treatment of cells with GNPs and IR. However, when EP is added to the protocol of GNPs+IR group (GNPs+EP+IR),
DEFs of 2.61 and 1.92 were observed in HT-29 and CHO cells, respectively. The observed difference between DEF values of GNPs+IR and GNPs+EP+IR groups can be attributed to the act of EP as a GNPs delivery system in GNPs+EP+IR group.

Incubation of the cells with GNPs $24 \mathrm{~h}$ prior to IR (GNPs $(24 \mathrm{~h})+\mathrm{IR})$ resulted in the DEF of 1.47 and 1.38, respectively, for HT-29 and CHO cells. However, these values reached to 2.89 and 2.26 in $\mathrm{HT}-29$ and $\mathrm{CHO}$, respectively, by introducing EP in this protocol $10 \mathrm{~min}$ before IR (GNPs (24 h)+EP+IR). In this group, EP showed no delivery system role. Indeed, the GNPs that could not enter to cells during $24 \mathrm{~h}$ were eliminated during washing cells with PBS, trypsination, and centrifuging processes prior to EP, and thus this radiosensitivity effect is related to intrinsic radiosensitivity of EP due to ROS generation.

Our findings support the previous studies that have investigated the radiosensitizing effect of GNPs alone. Different mechanisms have been proposed in these studies for radiosensitivity induced by GNPs. The cell cycle regulation or accumulation of DU-145 prostate cancer cells in G2/M phase as a most radiosensitive phase of cell cycle due to activation of CDK kinase was reported by Roa et $\mathrm{al}^{45}$ and Wang et al. ${ }^{40}$ Wang et $\mathrm{al}^{40}$ demonstrated that Glu-GNPs increased apoptosis by overexpression of Bax and caspase 3 and underexpression of Bcl-2 proteins. Other probable mechanisms are increasing of ROS production and DNA double strand break, and these have been proposed by Geng et $\mathrm{al}^{46}$ and Chithrani et al, ${ }^{7}$ respectively.

Radiosensitizing effect of GNPs is dependent on three important factors: size, concentration of GNPs, and energy of the ionization radiation source ${ }^{47}$ The effects of size and concentration of PEG-coated GNPs have been comprehensively investigated by Zhang et al. ${ }^{48}$ Their in vitro and in vivo studies revealed that for all sizes of 4.8, 12.1, 27.3, and $46.6 \mathrm{~nm}$, the concentration of $0.1 \mathrm{mM}$ was safe and nontoxic. The strongest radiosensitizing effect with SER of 2.07 was obtained with $12.1 \mathrm{~nm}$ GNPs at concentration of $0.1 \mathrm{mM}$. Similarly, in vivo radiotherapy demonstrated that all sizes of GNPs can enhance the effect of 5 Gy radiation. ${ }^{48}$ Similarly, we used 12-15 nm GNPs at concentration of $0.1 \mathrm{mM}$, and the results of MTT assay revealed that this dose of GNPs is safe for all incubation times of 24,48 , and $72 \mathrm{~h}$.

Several studies have been conducted on radiosensitivity effect of GNPs with $\mathrm{KV}$ radiations due to a $\mathrm{Z}^{4}$ relationship between photoelectric cross section and atomic number (Z). ${ }^{49,50}$ However, Jain et al ${ }^{51}$ comprehensively evaluated the impact of type and energy of radiation $(\mathrm{kV}$ and $\mathrm{MV}$ photons and MV electrons) on GNPs radiosensitizing. They reported 
that $1.9 \mathrm{~nm}$ GNPs could significantly sensitize MDA-MB231 breast cancer cells by a factor of $1.41,1.29,1.16$, and 1.35 using $160 \mathrm{kVp}, 6 \mathrm{MV}$, and $15 \mathrm{MV}$ X-ray photons, and $16 \mathrm{MeV}$ electrons, respectively. ${ }^{51}$ Furthermore, Wang et $\mathrm{al}^{40}$ reported that treatment of A549 cells with $13 \mathrm{~nm}$ Glu-GNPs and $6 \mathrm{MV}$ photons resulted in a DEF of 1.49. According to these results and because of the extensive uses of MV photons to treat deep tumors as well as spare skin of patients in clinic, we decided to use $6 \mathrm{MV}$ photons for irradiation.

In addition, the cell type is other factor that can influence the outcome of treatment with GNPs. During the recent years, the radiosensitizing feature of GNPs has been used to treat several cell lines such as prostate, ${ }^{11}$ breast, ${ }^{50,51}$ lung, ${ }^{40}$ ovarian, ${ }^{46}$ and colorectal ${ }^{52}$ cancer cell lines. Arab-Bafrani et $\mathrm{al}^{52}$ observed that the response of HT-29 colorectal cancer cell line to $9 \mathrm{MV}$ photons was increased by a factor of 1.4 using GNPs. Similarly, in our study using only GNPs $24 \mathrm{~h}$ prior to irradiation, a DEF of 1.47 was observed. However, the GNPs $(24 \mathrm{~h})+\mathrm{EP}+\mathrm{IR}$ protocol resulted in a DEF of 2.89 in the HT-29 cancer cell line. In addition, the synergistic effect was only observed in the HT-29 cell.

\section{Conclusion}

In conclusion, to our knowledge, this study was the first to use both GNPs and EP simultaneously to sensitize cells to 6 $\mathrm{MV}$ radiations. The most radiosensitizing effect was achieved with GNPs (24 h)+EP+IR protocol in HT-29 cell with intermediate intrinsic radiosensitivity. Therefore, this protocol has a potential to sensitize less radiosensitive tumor cells, and thus there is need for more in vivo studies to translate this approach into the clinic.

\section{Acknowledgments}

This study was a part of the MSc thesis registered in the Medical Physics department, School of Medicine, Ahvaz Jundishapur University of Medical Sciences (AJUMS), conducted in the Cellular and Molecular Research Center (CMRC) of AJUMS. Financial support for the study was provided by AJUMS (Grant No: CMRC-9428). The authors thank Mr Sadegh Saremi, the technical expert of the CMRC, for his technical supports during the conducting of this study. In addition, the authors thank Dr Mohammad Javad Tahmasebi Birgani for his help in arranging the using of the irradiation set up.

\section{Author contributions}

All authors made substantial contributions to conception and design, acquisition of data, or analysis and interpretation of data; took part in drafting the article or revising it critically for important intellectual content; gave final approval of the version to be published; and agree to be accountable for all aspects of the work.

\section{Disclosure}

The authors report no conflicts of interest in this work.

\section{References}

1. Hainfeld JF, Dilmanian FA, Slatkin DN, Smilowitz HM. Radiotherapy enhancement with gold nanoparticles. J Pharm Pharmacol. 2008; 60(8):977-985.

2. Hall EJ, Giaccia AJ. Radiobiology for the Radiologist. Philadelphia, PA: Lippincott Williams \& Wilkins; 2006.

3. Drouet F, Lagrange J. [Normal tissue tolerance to external beam radiation therapy: bone marrow]. Cancer Radiother. 2010;14(4-5):392-404. French.

4. Matsudaira H, Ueno AM, Furuno I. Iodine contrast medium sensitizes cultured mammalian cells to X rays but not to $\gamma$ rays. Radiat Res. 1980; 84(1):144-148.

5. Nishioka A, Ohizumi Y, Lam GK, et al. The effects of nicotinamide plus carbogen or pions for microscopic SCCVII tumors. Oncol Rep. 1999;6:583-586.

6. Shibamoto Y, Zhou L, Hatta H, Mori M, Nishimoto SI. In vivo evaluation of a novel antitumor prodrug, 1-(2'-oxopropyl)-5-fluorouracil (OFU001), which releases 5-fluorouracil upon hypoxic irradiation. Int J Radiat Oncol Biol Phys. 2001;49(2):407-413.

7. Chithrani DB, Jelveh S, Jalali F, et al. Gold nanoparticles as radiation sensitizers in cancer therapy. Radiat Res. 2010;173(6):719-728.

8. Hainfeld JF, Dilmanian FA, Zhong Z, Slatkin DN, Kalef-Ezra JA, Smilowitz HM. Gold nanoparticles enhance the radiation therapy of a murine squamous cell carcinoma. Phys Med Biol. 2010;55(11):3045.

9. Shil P, Sanghvi SH, Vidyasagar PB, Mishra KP. Enhancement of radiation cytotoxicity in murine cancer cells by electroporation: in vitro and in vivo studies. J Environ Pathol Toxicol Oncol. 2005;24(4):291-298.

10. West CM. A potential pitfall in the use of electroporation: cellular radiosensitization by pulsed high-voltage electric fields. Int $J$ Radiat Biol. 1992;61(3):329-334.

11. Zhang X, Xing JZ, Chen J, et al. Enhanced radiation sensitivity in prostate cancer by gold-nanoparticles. Clin Invest Med. 2008;31(3):160-167.

12. Joh DY, Sun L, Stangl M, et al. Selective targeting of brain tumors with gold nanoparticle-induced radiosensitization. PLoS One. 2013; 8(4):e62425.

13. Hainfeld JF, Slatkin DN, Smilowitz HM. The use of gold nanoparticles to enhance radiotherapy in mice. Cancer Res. 2005;65(Suppl 9):287.

14. Anijdan SH, Mahdavi SR, Shirazi A, Zarrinfard MA, Hajati J. Megavoltage X-ray dose enhancement with gold nanoparticles in tumor bearing mice. Int J Mol Cell Med. 2013;2(3):118-123.

15. Connor EE, Mwamuka J, Gole A, Murphy CJ, Wyatt MD. Gold nanoparticles are taken up by human cells but do not cause acute cytotoxicity. Small. 2005;1(3):325-327.

16. Mironava T, Hadjiargyrou M, Simon M, Jurukovski V, Rafailovich MH. Gold nanoparticles cellular toxicity and recovery: effect of size, concentration and exposure time. Nanotoxicology. 2010;4(1):120-137.

17. Shukla R, Bansal V, Chaudhary M, Basu A, Bhonde RR, Sastry M. Biocompatibility of gold nanoparticles and their endocytotic fate inside the cellular compartment: a microscopic overview. Langmuir. 2005;21(23):10644-10654.

18. Pan Y, Neuss S, Leifert A, et al. Size-dependent cytotoxicity of gold nanoparticles. Small. 2007;3(11):1941-1949.

19. Cho SH. Estimation of tumour dose enhancement due to gold nanoparticles during typical radiation treatments: a preliminary Monte Carlo study. Phys Med Biol. 2005;50(15):N163. 
20. Roeske JC, Nuñez L, Hoggarth M, Labay E, Weichselbaum RR. Characterization of the theorectical radiation dose enhancement from nanoparticles. Technol Cancer Res Treat. 2007;6(5):395-401.

21. Chang MY, Shiau AL, Chen YH, Chang CJ, Chen HH, Wu CL. Increased apoptotic potential and dose-enhancing effect of gold nanoparticles in combination with single-dose clinical electron beams on tumor-bearing mice. Cancer Sci. 2008;99(7):1479-1484.

22. Jordan CA, Neumann E, Sowers AE. Electroporation and Electrofusion in Cell Biology. New York, NY: Springer Science \& Business Media; 2013.

23. Tsong TY. Electroporation of cell membranes. Biophys J. 1991; 60(2):297.

24. Pavlin M, Leben V, Miklavčič D. Electroporation in dense cell suspension - theoretical and experimental analysis of ion diffusion and cell permeabilization. Biochim Biophys Acta. 2007;1770(1):12-23.

25. Weaver JC. Molecular basis for cell membrane electroporationa. Ann N Y Acad Sci. 1994;720(1):141-152.

26. Haltiwanger S. Why electroporation is a useful technique for cancer treatments. In: Sundararajan R, editor. Electroporation-Based Therapies for Cancer: From Basics to Clinical Applications. Cambridge, UK: Elsevier; 2014:103.

27. Mir LM, Orlowski S. The basis of electrochemotherapy. In: Jaroszeski MJ, Heller R, Gilbert R, editors. Electrochemotherapy, Electrogenetherapy, and Transdermal Drug Delivery: Electrically Mediated Delivery of Molecules to Cells. Totowa, NJ: Humana Press; 2000:99-117.

28. Yadollahpour A, Rezaee Z. Electroporation as a new cancer treatment technique: a review on the mechanisms of action. Biomed Pharmacol J. 2014;7(1):53-62.

29. Kandušer M, Miklavčič D. Electroporation in biological cell and tissue: an overview. In: Electrotechnologies for Extraction from Food Plants and Biomaterials. New York, NY: Springer; 2009:1-37.

30. Kinosita K, Hibino M, Itoh H, et al. Events of membrane electroporation visualized on a time scale from microsecond to seconds. Paper presented at: Elsevier Inc; 2012.

31. Onik G, Mikus P, Rubinsky B. Irreversible electroporation: implications for prostate ablation. Technol Cancer Res Treat. 2007;6(4):295-300.

32. Rubinsky B. Irreversible electroporation in medicine. Technol Cancer Res Treat. 2007;6(4):255-259.

33. Widera G, Austin M, Rabussay D, et al. Increased DNA vaccine delivery and immunogenicity by electroporation in vivo. $J$ Immunol. 2000;164(9):4635-4640.

34. Zhang GH, Tan XF, Shen D, et al. Gene expression and antitumor effect following im electroporation delivery of human interferon 2 gene. Acta Pharmacol Sin. 2003;24(9):891-896.

35. Quaglino P, Mortera C, Osella-Abate S, et al. Electrochemotherapy with intravenous bleomycin in the local treatment of skin melanoma metastases. Ann Surgical Oncol. 2008;15(8):2215-2222.

36. Gabriel B, Teissie J. Generation of reactive-oxygen species induced by electropermeabilization of Chinese hamster ovary cells and their consequence on cell viability. Eur J Biochem. 1994;223(1):25-33.
37. Gabriel B, Teissie J. Spatial compartmentation and time resolution of photooxidation of a cell membrane probe in electropermeabilized Chinese hamster ovary cells. Eur J Biochem. 1995;228(3):710-718.

38. Zu Y, Huang S, Liao WC, Lu Y, Wang S. Gold nanoparticles enhanced electroporation for mammalian cell transfection. J Biomed Nanotechnol. 2014;10(6):982-992.

39. Franken NA, Rodermond HM, Stap J, Haveman J, Van Bree C. Clonogenic assay of cells in vitro. Nat Protoc. 2006;1(5):2315-2319.

40. Wang C, Li X, Wang Y, Liu Z, Fu L, Hu L. Enhancement of radiation effect and increase of apoptosis in lung cancer cells by thioglucose-bound gold nanoparticles at megavoltage radiation energies. J Nanoparticle Res. 2013;15(5):1-12.

41. Kranjc S, Cemazar M, Grosel A, Sentjurc M, Sersa G. Radiosensitising effect of electrochemotherapy with bleomycin in LPB sarcoma cells and tumors in mice. BMC Cancer. 2005;5(1):1.

42. Bonnafous P, Vernhes MC, Teissié J, Gabriel B. The generation of reactive-oxygen species associated with long-lasting pulse-induced electropermeabilisation of mammalian cells is based on a non-destructive alteration of the plasma membrane. Biochim Biophys Acta. 1999; 1461(1):123-134.

43. Shil P, Sanghvi SH, Vidyasagar PB, Mishra KP. Enhancement of radiation cytotoxicity in murine cancer cells by electroporation: In vitro and in vivo studies. J Environ Pathol Toxicol Oncol. 2005;24(4):291-298.

44. Song K, Xu P, Meng Y, et al. Smart gold nanoparticles enhance killing effect on cancer cells. Int J Oncol. 2013;42(2):597-608.

45. Roa W, Zhang X, Guo L, et al. Gold nanoparticle sensitize radiotherapy of prostate cancer cells by regulation of the cell cycle. Nanotechnology. 2009;20(37):375101.

46. Geng F, Song K, Xing JZ, et al. Thio-glucose bound gold nanoparticles enhance radio-cytotoxic targeting of ovarian cancer. Nanotechnology. 2011;22(28):285101.

47. Brun E, Sanche L, Sicard-Roselli C. Parameters governing gold nanoparticle X-ray radiosensitization of DNA in solution. Colloids Surf B Biointerfaces. 2009;72(1):128-134.

48. Zhang XD, Wu D, Shen X, et al. Size-dependent radiosensitization of PEG-coated gold nanoparticles for cancer radiation therapy. Biomaterials. 2012;33(27):6408-6419.

49. Khoshgard K, Hashemi B, Arbabi A, Rasaee MJ, Soleimani M. Radiosensitization effect of folate-conjugated gold nanoparticles on HeLa cancer cells under orthovoltage superficial radiotherapy techniques. Phys Med Biol. 2014;59(9):2249.

50. Kong T, Zeng J, Wang X, et al. Enhancement of radiation cytotoxicity in breast-cancer cells by localized attachment of gold nanoparticles. Small. 2008;4(9):1537-1543.

51. Jain S, Coulter JA, Hounsell AR, et al. Cell-specific radiosensitization by gold nanoparticles at megavoltage radiation energies. Int J Radiat Oncol Biol Phys. 2011;79(2):531-539.

52. Arab-Bafrani Z, Saberi A, Birgani MJT, Shahbazi-Gahrouei D, Abbasian M, Fesharaki M. Gold nanoparticle and mean inactivation dose of human intestinal colon cancer HT-29 cells. Jundishapur J Nat Pharm Prod. 2015;10(4):e29153.
International Journal of Nanomedicine

\section{Publish your work in this journal}

The International Journal of Nanomedicine is an international, peerreviewed journal focusing on the application of nanotechnology in diagnostics, therapeutics, and drug delivery systems throughout the biomedical field. This journal is indexed on PubMed Central, MedLine, CAS, SciSearch ${ }^{\circledR}$, Current Contents ${ } /$ Clinical Medicine,

\section{Dovepress}

Journal Citation Reports/Science Edition, EMBase, Scopus and the Elsevier Bibliographic databases. The manuscript management system is completely online and includes a very quick and fair peer-review system, which is all easy to use. Visit http://www.dovepress.com/ testimonials.php to read real quotes from published authors. 